\title{
AN ALGORITHM OF A FREEFORM SURFACES MEASUREMENT ADJUSTMENT USING A SPECIFICATION OF THE WORKPIECE COORDINATE SYSTEM LOCATION
}

\author{
Ján Buša ${ }^{1}$, Ján Buša Jr. ${ }^{1}$, Miroslav Dovica ${ }^{2}$, Michal Fabiann', Peter Ižol ${ }^{2}$, Stanislav Honus ${ }^{3}$ \\ 1 Faculty of Electrical Engineering and Informatics, Technical University of Košice, Letná 9, 042 00, Košice, Slovak \\ Republic, e-mail: jan.busa@tuke.sk \\ 2 Faculty of Mechanical Engineering, Technical University of Košice, Letná 9, 042 00, Košice, Slovak Republic, \\ e-mail: miroslav.dovica@tuke.sk; michal.fabian@tuke.sk; peter.izol@tuke.sk \\ 3 VŠB - Technical University of Ostrava, 17. listopadu 15/2172, 70833 Ostrava - Poruba, Czech Republic
}

Received: 2017.06 .24

Accepted: 2017.08.01

Published: 2017.09.03

\begin{abstract}
A difficulty of freeform surfaces evaluations lies in a setup of a coordinate measuring system in general, when it is not possible to use the standard system of alignment by a point, a line, and a surface. An algorithm for the measurement adjustment using a small workpiece coordinate system movement and rotation to achieve a smaller least square error of the produced surface for a given freeform surface defined by the function of two variables is considered. The algorithm uses the Newton method for calculation of the orthogonal distance of a measured point to a given surface and also for minimization of the sum of the distance squares. Numerical results for an example are given.
\end{abstract}

Keywords: freeform surface, cloud of points, Nelder-Mead method, Newton method.

\section{INTRODUCTION}

Implementation of CAx systems into the process of design, production, and measurement in the mechanical engineering had a considerable impact on the product design, mainly in the consumer goods and automotive industries. CAx systems development is still ongoing and allows creating freeform surfaces as well as precise surfaces that are empirically described by mathematical equations. The form surface defined by mathematical expression enables us to obtain the exact shape, which is subsequently produced on a CNC machine. This whole process affects the quality of machined surfaces.

Freeform surfaces are still considered to be artists' not engineers' work. The paradox is that mass production of freeform surfaces were enabled mainly by engineering. In spite of these, the freeform surfaces are around us more and more.
The freeform surfaces have become the reality of series production in aviation, automotive and consumer goods industry at the time when modern optoelectronic scanning devices and CAD systems entered the re-engineering process. This issue was elaborated by Ohara and Higashi already in 1983 [1], Mehrad, Xue, and Gu in [2], Sitnik and Blaszczyk in [3], Garbacz et. al. in [21] or Molnár et. al. in [19]. Modern scanners can deliver numerical information of the product geometry in a form of $\mathrm{x}, \mathrm{y}, \mathrm{z}$ coordinates - so-called clouds of points.

These can be then loaded into CAD systems, triangulated and after making cross cuts of this triangulated data we can identify the cross section curves. This allows us to define smooth shape surfaces.

Reverse engineering process is a subject of interest to engineers and scientists and is being constantly improved. Oe, Shizuki, and Tanaka discuss this topic in [4] and Kruth and Kersten 

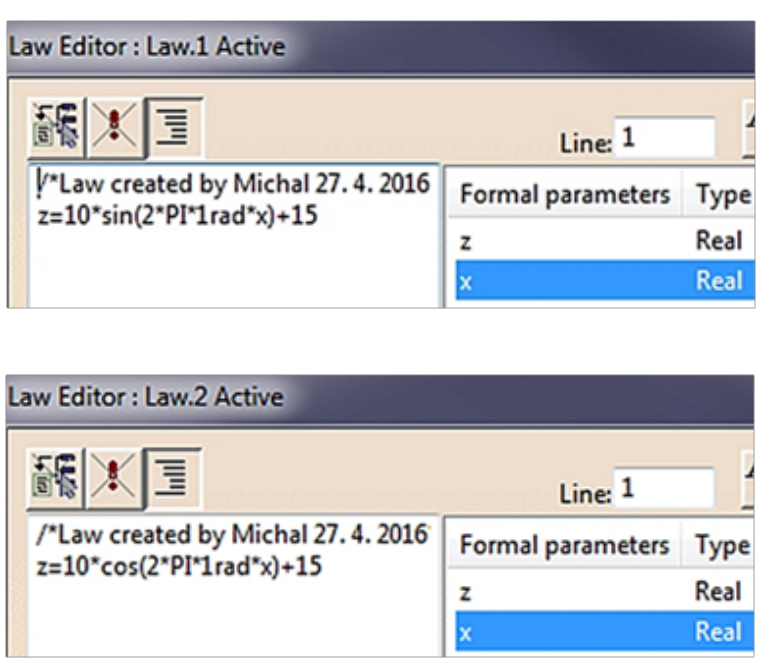

Fig. 1. Sine (above) and cosine (below) function in the CATIA Law Editor

in [5]. The process is completed when perfectly smooth surfaces are created and subsequently forwarded to a toolroom. Wu, Yang, and Guo deal with it in [6]. Ochiai and Sekiya discussed about generation of freeform surface in CAD for dies in 1995 in [7]. About CNC machining freeform surfaces discuss Lo in [8], Wei and Lin in [9], and Sacharow et. al. in [10].

The accuracy of workpieces of complex freeform surfaces is achieved by tolerancing, producing, and metrology of workpieces. The tolerance zone is defined by form tolerances, their orientation, and location on the workpieces. Tolerances for complex form surfaces are specified by line profile tolerance or surface profile tolerance. These tolerances control form or combination of size, form, orientation, and location. This issue was elaborated by Král' and Král' [22]. In a machining process, the impact of machining parameter settings on the final surface quality will be studied. For geometry verification of the complex form surfaces the coordinate measurements will be used. The measurement area will in CATIA V5 be modeled by equations. The data of machined surface will be obtained through 3D measurement.

The issue of measurement and obtaining the shape will be solved by the contact measurement using contact scanners or without contact via optoelectronic scanners. This issue is addressed by Fanf and Zhang Qiu in [11] and Debski et. al. in [20]. Lee and Shiou [12] and Kale and Gurumoorthy [13], Fedorko et. al [23] and Kulka et. al [24] deal with the issue of freeform surface measurement.

\section{WORKPIECE MANUFACTURING AND QUALITY CONTROL}

This work discusses the creation of surface defined by limiting curves that are set by sine profile of limiting curves on one side and cosine profile of limiting curve on other. This shape simulated freeform surface defined by mathematical functions (sine and cosine) in CATIA. This model was applied when producing the gauge called SC01 that was consequently measured. Accordingly, second model was designed. Its basic shape was defined by cloud of points generated in MATLAB. Such cloud was approximated by surface that was produced and named MR02. This model was measured, too.

\section{Mathematical definition of surfaces in CATIA V5}

For this research, it was necessary to produce two artifacts. As it was already mentioned, the first artifact was defined by two limits defined by mathematical function on which the surface is put using Multisection surface command in CATIA V5. Firstly, it was necessary to input parameters
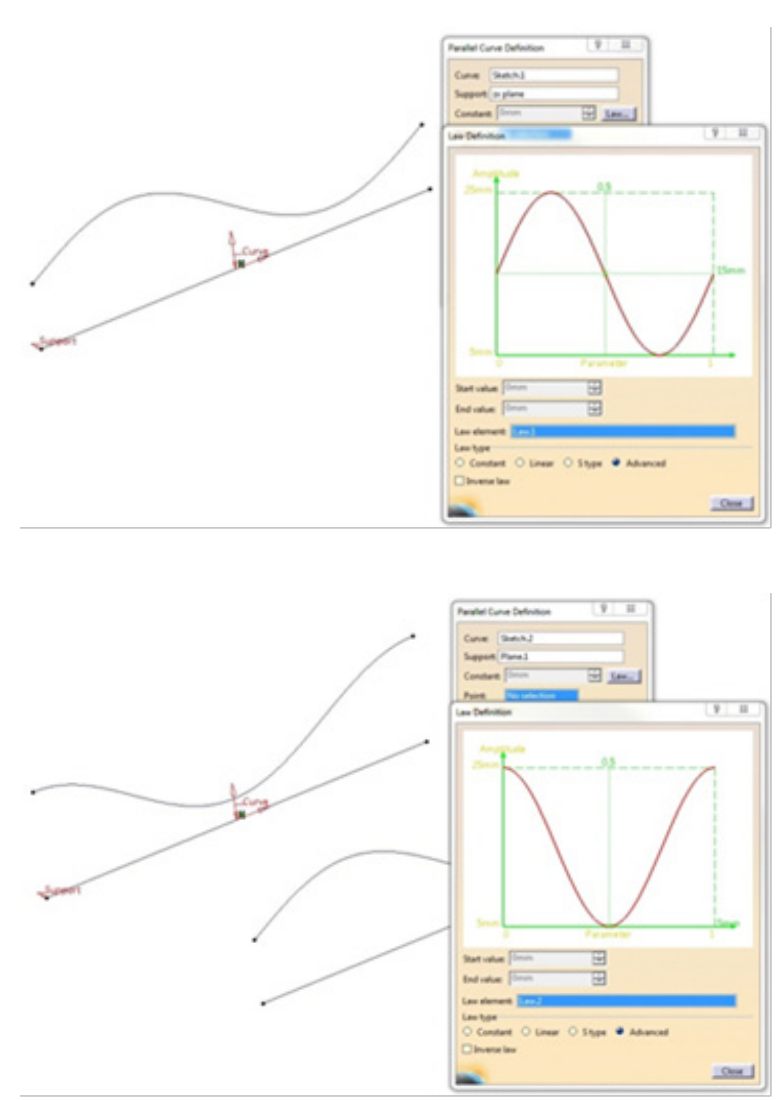

Fig. 2. Definition of sine (above) and cosine (below) curves in CATIA V5 

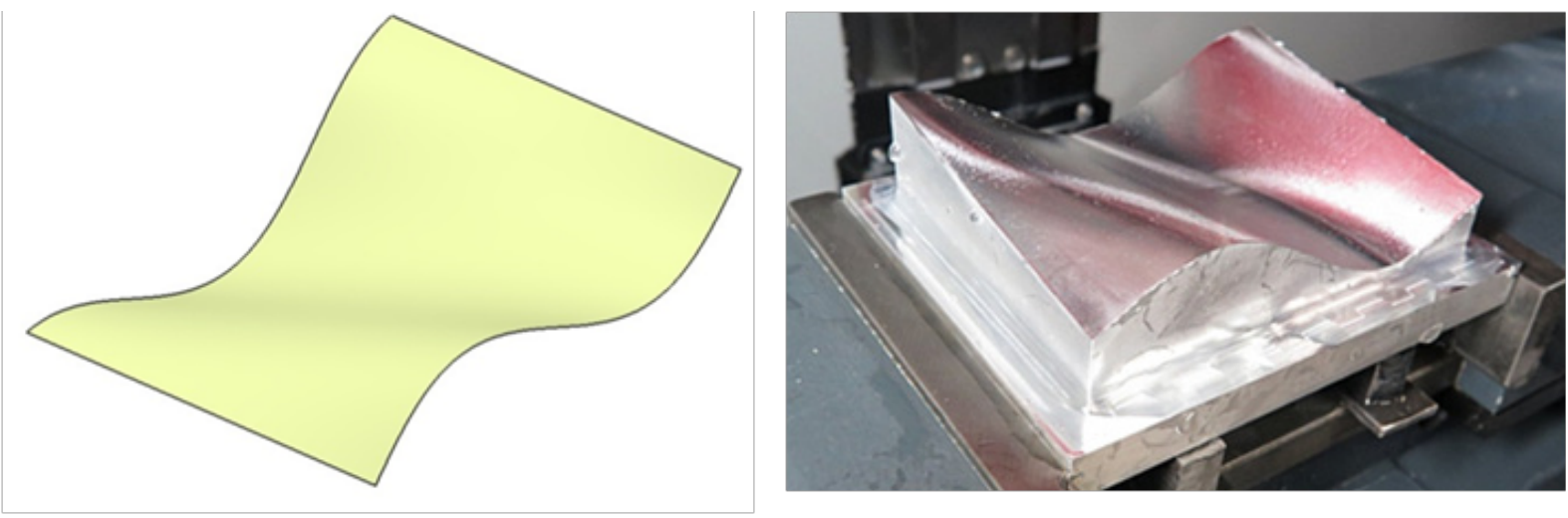

Fig. 3. Final surface defined by the sine and cosine functions (left) and part produced by a milling machine (right)

and equations. Equations were defined in CATIA Law Editor (Fig. 1).

Curves defined by sine in Eq. (1) and cosine functions in Eq. (2) created limits to create the surface of sample SC01 (Fig. 2).

The inserted functions are of the form:

$$
\begin{aligned}
& Z=15+10 \cdot \sin \frac{2 \pi x}{100} \\
& Z=15+10 \cdot \cos \frac{2 \pi x}{100}
\end{aligned}
$$

The final virtual freeform surface is shown in Figure 3. Furthermore, it was used to generate $\mathrm{CNC}$ program for production of artifact on $3 \mathrm{D}$ milling machine EMCO Concept Mill 155.

\section{Surface defined by cloud of points in CATIA V5}

The second surface model was designed using cloud of points generated in MATLAB according to Eq. (16). This cloud was then imported in the environment Digitized Shape Editor in CATIA V5. Final form of the surface was cre- ated by putting the surface onto the cloud using command Power Fit (Fig. 4). As such, the surface MR02 was created. The second artifact was also produced using 3D CNC Milling Machine.

\section{Artifact manufacturing}

On the basis of the surface model, CNC data were generated for production samples that were afterward subjected to measurements. The artifacts were milled into aluminum and machined by ball end tool on EMCO Concept Mill 155 milling machine. Machining strategy is in transversal direction when the main movement of the tool is in the width direction of the workpiece (yaxis) (Fig. 5 a) using the isoparametric machining strategy (Fig. 5 b). At first we rough the stock of material and after that make finishing operation (Fig. 6). The distance between two successive toolpaths was recalculated on the basis of a height inequality value setting (Scallop Height), (see Fig. 7). The maximum Scallop Height value was set to $0.001 \mathrm{~mm}$.

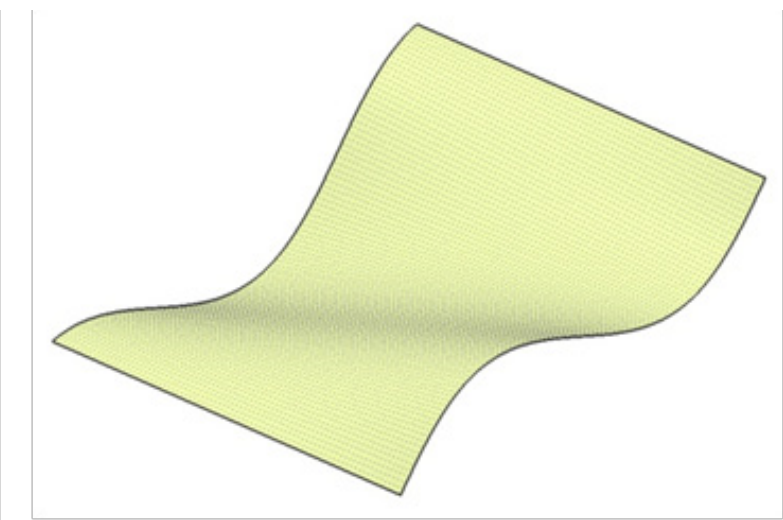

Fig. 4. Cloud of points (left) import to CATIA and surface based on this cloud of points (right) 

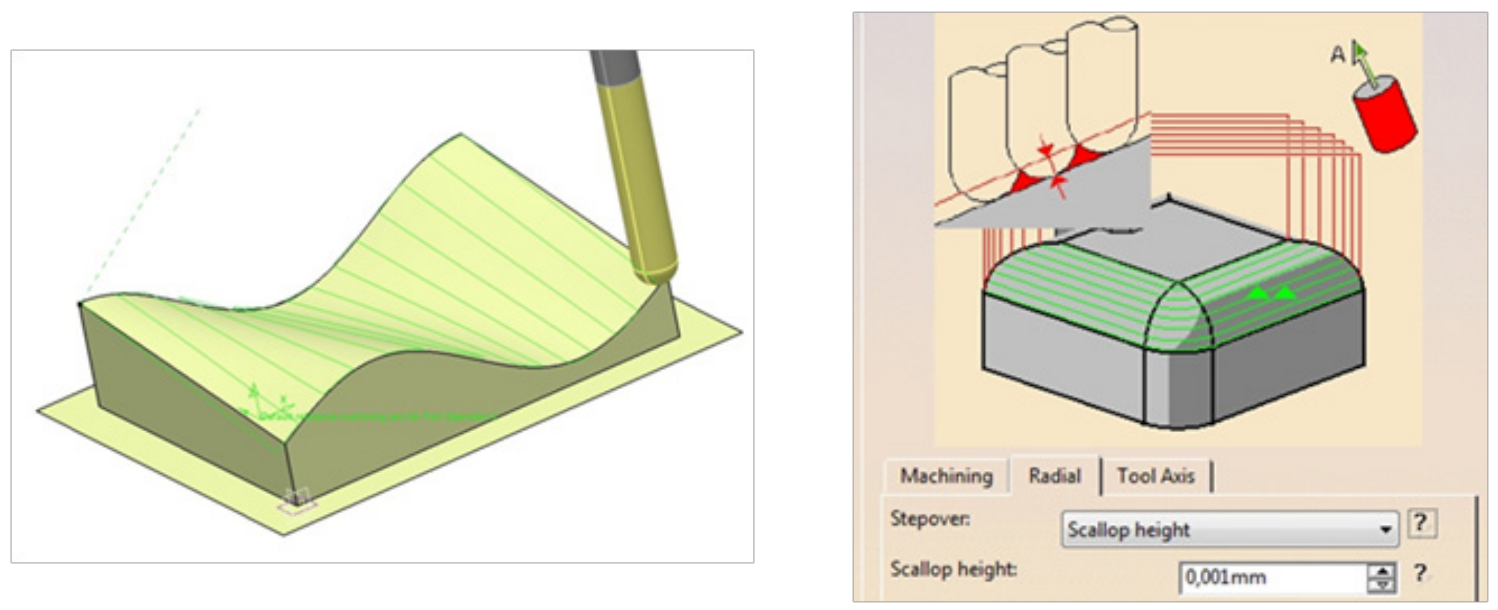

Fig. 5. Definition of machining strategy - movement of the tool (left) and parameters of isoparametric machining strategy (right)
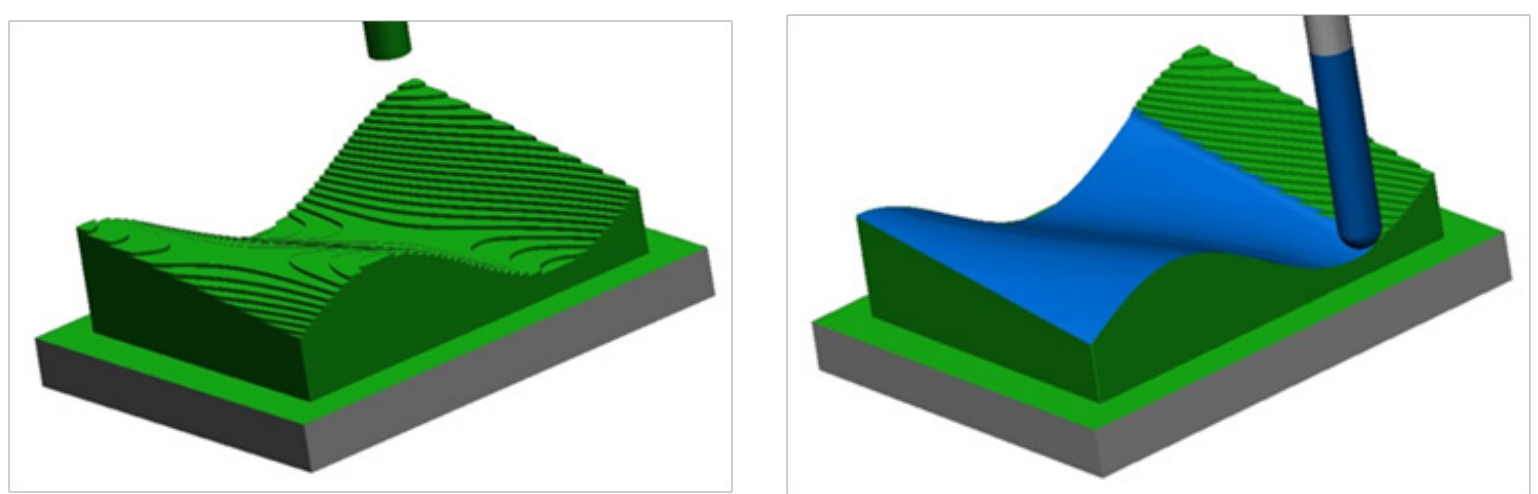

Fig. 6 Roughing (left) and finishing (right) operation

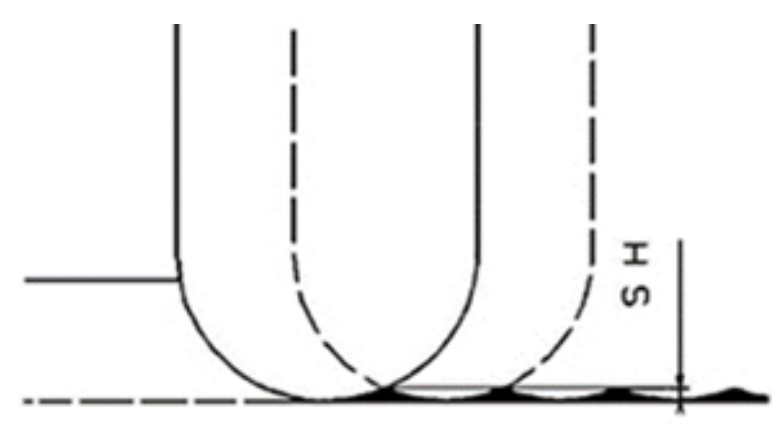

Fig. 7. SH (Scallop Height) - height inequality parameter setting

\section{Measurement system}

In the area of 3D measurement of machine parts, the 3D imaging devices are used thanks to their advantageous speed and accuracy. Portable coordinate measuring machine (CMM) FARO Arm was applied to measure two physical parts of freeform modeled in the
CATIA environment. 3D non-contact measurement was used. Repeatability, based on working volume, was in the interval from $0.024 \mathrm{~mm}$ to $0.064 \mathrm{~mm}$. In this case, the repeatability equaled to $0.034 \mathrm{~mm}$. Measured clouds of points were saved in two separate files. The first file sc01.dat (containing 3707 474 points) and the second one mr02.dat (containing 3774502 points). Loading these files into the Octave took about 23 seconds. After the transformation to the binary format, loading time has been reduced to about 0.5 second or even less.

\section{WORKPIECE MANUFACTURING AND QUALITY CONTROL}

In this section an algorithm for a measurement adjustment using a small workpiece coordinate system movement and rotation to achieve a 
smaller least squares error of the produced surface for a given freeform surface defined by a function of two variables is considered.

\section{Orthogonal distance}

Let us consider a function

$$
z=f(x, y), \quad(x, y) \in R
$$

where: $\mathrm{R}$ denotes a rectangle $\left[0,1_{\mathrm{x}}\right] \times\left[0,1_{\mathrm{y}}\right]\left(1_{\mathrm{x}}>0\right.$ and $\mathrm{l}_{\mathrm{y}}>0$ are the corresponding rectangle's sides lengths). Here we suppose that the function $f(x, y)$ has continuous derivatives of the second order with respect to both variables.

Let us consider a "measured" point $\mathrm{P}=\left(\hat{\mathrm{x}}_{\mathrm{p}} ; \hat{\mathrm{y}}_{\mathrm{p}} ; \mathrm{z}_{\mathrm{p}}\right)$ close to the surface $\mathrm{S}$ given as a graph of the function $\mathrm{f}(\mathrm{x}, \mathrm{y})$, e.g.,

$$
S=\{(x, y, f(x, y)) \mid(x, y) \in R\}
$$

Our goal is to determine a projection $\mathrm{P}^{\mathrm{S}}$ of the point $\mathrm{P}$ onto the surface $\mathrm{S}$ and the distance between the points $\mathrm{P}$ and $\mathrm{P}^{\mathrm{S}}$. So we are led to the minimization of the problem

$$
\left\|P^{S}-P\right\|_{2}=\min _{(x, y)}\left\|(x, y, f(x, y))-\left(\hat{x} ; \hat{y}_{P} ; z_{P}\right)\right\|_{2}
$$

where $\| \mathrm{P}^{\mathrm{S}}$ - $\mathrm{P} \|_{2}$ denotes the Euclidean distance. Instead of the minimization of Eq. (5) we have minimized a square of the distance, hence we were looking for the minimum of the function

$$
D^{2}(x, y)=\left(x-\hat{x}_{P}\right)^{2}+\left(y-\hat{y}_{P}\right)^{2}+\left(f(x, y)-z_{P}\right)^{2}
$$

We numerically solved a set of nonlinear equations for the stationary point $\left(\mathrm{x}_{*}, \mathrm{y}_{*}\right)$ corresponding to the zero gradient of the function $\mathrm{D}^{2}$ :

$$
\begin{gathered}
\left(x_{*}-\hat{x}_{P}\right)+\left(f\left(x_{*}, y_{*}\right)-z_{P}\right) \cdot f_{x}^{\prime}\left(x_{*}, y_{*}\right)=0, \\
\left(y_{*}-\hat{y}_{P}\right)+\left(f\left(x_{*}, y_{*}\right)-z_{P}\right) \cdot f_{y}^{\prime}\left(x_{*}, y_{*}\right)
\end{gathered}
$$

using the Newton method [14]. This is equivalent to the minimization of $\mathrm{D}^{2}$ by the Newton method [15]. In this case the Jacobian matrix for the system of nonlinear equations is equal to the Hessian matrix. Because the point $\left(\mathrm{x}_{\mathrm{p}}, \mathrm{y}_{\mathrm{p}}\right)$ is supposed to be close to the point $\left(\mathrm{x}_{*}, \mathrm{y}_{*}\right)$, two Newton iterations provided sufficient precision for approximation of the point $\left(\mathrm{x}_{*}, \mathrm{y}_{*}\right)$. For approximation of projection, point $\mathrm{P}_{2}$ has been used:

$$
P^{S} \approx P_{2}=\left(x_{2}, y_{2}, f\left(x_{2}, y_{2}\right)\right)
$$

where $\left(\mathrm{x}_{0}, \mathrm{y}_{0}\right)=\left(\hat{\mathrm{x}}_{\mathrm{p}} ; \hat{\mathrm{y}}_{\mathrm{p}}\right)$ has been used as an initial approximation for the Newton method.

Afterwards the orthogonal distance of the point $\mathrm{P}$ to the surface $\mathrm{S}$ has been approximated by

$$
D\left(\hat{x}_{P}, \hat{y}_{P}, z_{P}\right)=\sqrt{\left(\hat{x}_{P}-x_{2}\right)^{2}+\left(\hat{y}_{P}-y_{2}\right)^{2}+\left(z_{P}-f\left(x_{2}, y_{2}\right)\right)^{2}}
$$

\section{Minimization of the sum of squares of distances}

Let set of measured points

$$
\begin{array}{ccc}
x_{P 1} & y_{P 1} & z_{P 1} \\
x_{P 2} & y_{P 2} & z_{P 2} \\
\vdots & \vdots & \vdots \\
x_{P N} & y_{P N} & z_{P N}
\end{array}
$$

of size $\mathrm{N}$ be given. If coordinates $\mathrm{x}_{\mathrm{Pi}}, \mathrm{y}_{\mathrm{Pi}}, \mathrm{z}_{\mathrm{Pi}}, \mathrm{i}=1,2, \ldots, \mathrm{N}$ correspond to the coordinates $\mathrm{x}, \mathrm{y}$, and $\mathrm{z}$ of the graph above the rectangle $\mathrm{R}$, then we need only to calculate the sum of distances squares to get the mean distance $\mathrm{d}_{\text {mean }}$ : 


$$
\mathrm{RSS}=\sum_{i=1}^{N} D^{2}\left(x_{P_{i}}, y_{P_{i}}, z_{P_{i}}\right), \quad d_{\text {mean }}=\sqrt{\frac{\mathrm{RSS}}{N}}
$$

The RSS value is one of the characteristics of the workpiece production quality depending, however, on the number of points. Standard deviation $\mathrm{d}_{\text {mean }}$ can be used for the comparison of the precision for two points sets with the different numbers of points.

If we suppose that all points $P_{i}$ are lying exactly on the surface, then evidently $d_{\text {mean }}=0$. If, for any reason, the workpiece coordinate system will be displaced (moved in some direction and rotated in the $(\mathrm{x}, \mathrm{y})$ plane), then the measuring device will give us "surface points" which will not be laying on the surface, if we use the same coordinates in the workpiece coordinate system, and the mean distance value will be $\mathrm{d}_{\text {mean }}>0$. In that case we are able to recognize the workpiece coordinate system displacement by minimizing the value $\mathrm{d}_{\text {mean }}$ with respect to the possible shift and rotation.

We propose to apply the same idea in the case of a general measurement of the near-surface points. Suppose that the workpiece coordinate system origin $\mathrm{O}_{\mathrm{w}}$ is located at the point $\left(\mathrm{x}_{\mathrm{w}}, \mathrm{y}_{\mathrm{w}}\right)$ and the system is rotated by an angle $\alpha_{w}$ (see Fig. 8) with respect to the measuring device coordinate system. Then the "measured point" $\mathrm{x}$ - and $\mathrm{y}$-coordinates are "tainted". We are looking for the values $\mathrm{x}_{\mathrm{w}}, \mathrm{y}_{\mathrm{w}}$ and $\alpha_{\mathrm{w}}$. We define the optimal values $x_{w}, y_{w}$ and $\alpha_{w}$ as the values, for which the RSS value for a given set of measured points is minimal.

We propose to apply the same idea in $t \alpha_{w}$ he case of a general measurement of the near-surface points. Suppose that the workpiece coordinate system origin $\mathrm{O}_{\mathrm{w}}$ is located at the point $\left(\mathrm{x}_{\mathrm{w}}, \mathrm{y}_{\mathrm{w}}\right)$ and the system is rotated by an angle $\alpha_{w}$ (see Fig. 8) with respect to the measuring device coordinate system.

Then the "measured point" $\mathrm{x}$ - and $\mathrm{y}$ - coordinates are "tainted". We are looking for the values $\mathrm{x}_{\mathrm{w}}, \mathrm{y}_{\mathrm{w}}$ and $\alpha_{w}$. We define the optimal values $x_{w}, y_{w}$ and $\alpha_{w}$ as the values, for which the RSS value for a given set of measured points is minimal.

If we denote by $\tilde{\mathrm{P}}_{\mathrm{w}}$ the local "workpiece" coordinates of the projection $\tilde{\mathrm{P}}=\left(\mathrm{x}_{\mathrm{P}}, \mathrm{y}_{\mathrm{P}}\right)$ of a point $\mathrm{P}$ onto the $\mathrm{x}-\mathrm{y}$ plane, then we have

$$
\tilde{P}=\mathcal{O}_{w}+R(\alpha) \cdot \tilde{P}_{w}, \quad \tilde{P}_{w}=R(-\alpha) \cdot\left(\tilde{P}-\mathcal{O}_{w}\right)
$$

where $R(\alpha)$ is a rotation matrix for the angle $\alpha$.

Hence, the true "workpiece" coordinates of the projection $\tilde{P}$ are then given by the following formulas

$$
\begin{aligned}
& \hat{x}_{P}=\left(x_{P}-x_{w}\right) \cdot \cos \alpha_{w}+\left(y_{P}-y_{w}\right) \cdot \sin \alpha_{w} \\
& \hat{y}_{P}=\left(y_{P}-y_{w}\right) \cdot \cos \alpha_{w}-\left(x_{P}-x_{w}\right) \cdot \sin \alpha_{w}
\end{aligned}
$$

and we are indeed to determine the distance of the point $\left(\hat{\mathrm{x}}_{\mathrm{P}} ; \mathrm{y}_{\mathrm{P}} ; \mathrm{z}_{\mathrm{P}}\right)$ to the surface $S$.

Thus the residual sum of squares depends on the values $x_{D}, y_{D}$ and $\alpha_{D}$ :

$$
\operatorname{RSS}\left(x_{D}, y_{D}, \alpha_{D}\right)=\sum_{i=1}^{N} D^{2}\left(\hat{x}_{P_{i}}, \hat{y}_{P_{i}}, z_{P_{i}}\right)
$$

and can be minimized with respect to these values.

For the minimization of the function (14) we were using the inexact Newton method based on the inexact gradient and the Hessian matrix [15] defined by the finite difference method. Point $\mathrm{O}^{\prime}=\left(\mathrm{x}_{\mathrm{w}}^{\prime}, \mathrm{y}_{\mathrm{w}}^{\prime}\right)\left(\mathrm{x}_{\mathrm{w}}^{\prime}\right.$ is the leftmost $x$-coordinate and $y^{\prime}{ }_{w}$ is the smallest $y$-coordinate of all cloud points - see Fig. 8) for expected small angle $\alpha_{w}$ is serving as a good approximation of the origin $\mathrm{O}$.

Further we will use (see Fig. 8)

$$
x_{w}=x_{w}^{\prime}+\Delta x_{w}, y_{w}=y_{w}^{\prime}+\Delta y_{w}
$$

One two-dimensional and one three-dimensional Newton step have been sufficient to achieve good precision.

\section{NUMERICAL RESULTS}

Let us consider a function

$$
f(x, y)=15+10 \cdot\left[\left(1-\frac{y}{80}\right) \cdot \cos \frac{\pi x}{50}-\frac{y}{80} \cdot \sin \frac{\pi x}{50}\right]
$$




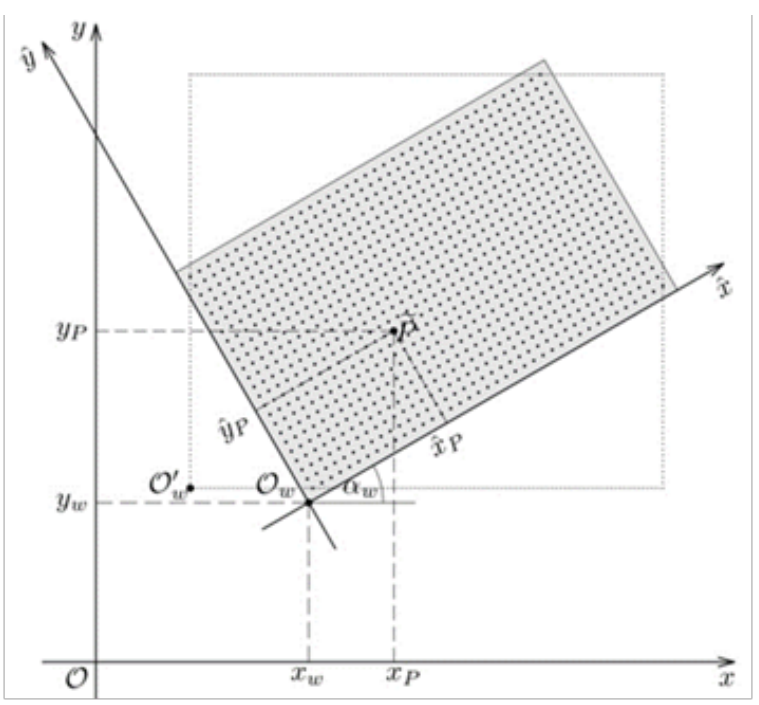

Fig. 8. Measurement device and workpiece coordinate systems

where: $\mathrm{x} \in[0,100], \mathrm{y} \in[0,80]$ with units in $\mathrm{mm}$. So therectangle $R$ has the size $100 \mathrm{~mm} \times$ $80 \mathrm{~mm}$ (see Fig. 9).

Below we will compare some results using the Nelder-Mead method [16] implemented in Octave with the results of the Newton method.

\section{Using the Nelder-Mead method}

Due to the large number of points and relatively slow computations in Octave only thousandth of points (step 1000) has been used for optimization. The results are shown in Table 1.

For computations an Octave function fminsearch.m written by S. Pelissier in 2006 has been used. It used a function fmins.m written by A. Adler in 2003 who modified for Octave the function nmsmax.m written by N.J. Higham [17], [18] in 2002.
During the optimization 111 function evaluations have been performed for sc01.dat and 114 for mr02.dat.

From experiments it is obvious, that the quality is much better after the location and rotation of the measurement device coordinate system - using the origin $\mathrm{O}_{\mathrm{w}}^{\prime}$ leads to much more pessimistic estimation of the mean "error". All characteristics were better for the data mr02.dat.

\section{Using the inexact Newton method}

For the inexact Newton method applications based on the finite difference approximation of partial derivatives different approaches have been compared. From the point of view of the computational time, the best performance has been achieved using one two-dimensional Newton step for $\Delta \mathrm{x}_{\mathrm{w}}$ and $\mathrm{y}_{\mathrm{w}}$ approximation without the rotation, and next one three-dimensional Newton step for $\left(\Delta \mathrm{x}_{\mathrm{w}}\right.$, $\left.\mathrm{y}_{\mathrm{w}}, \alpha_{\mathrm{w}}\right)$ and approximation. Moreover, the evaluation of the inexact gradient and Hessian matrix has been "optimized" using a common function.

The results for $\left(\Delta \mathrm{x}_{\mathrm{w}}, \mathrm{y}_{\mathrm{w}}, \alpha_{\mathrm{w}}=0,0,0\right)$ given in Table 2 are the same as in Table 1, and are not shown here. The first part of Table 2 refers to the results of the first two-dimensional Newton step which uses 11 functional value evaluations, and which is approximately two times faster than one three-dimensional Newton step which uses 20 functional value evaluations.

Here we can see that the first two-dimensional step will supply the main improvement of the measurement results interpretation. Therefore, the second step can be omitted if we have no time for its realization. The $\mathrm{C}++$ implementation of the program is much faster than the Octave implementation. The speedup for the smaller problems is about 800 , for the full set of points the speedup is about 41 .

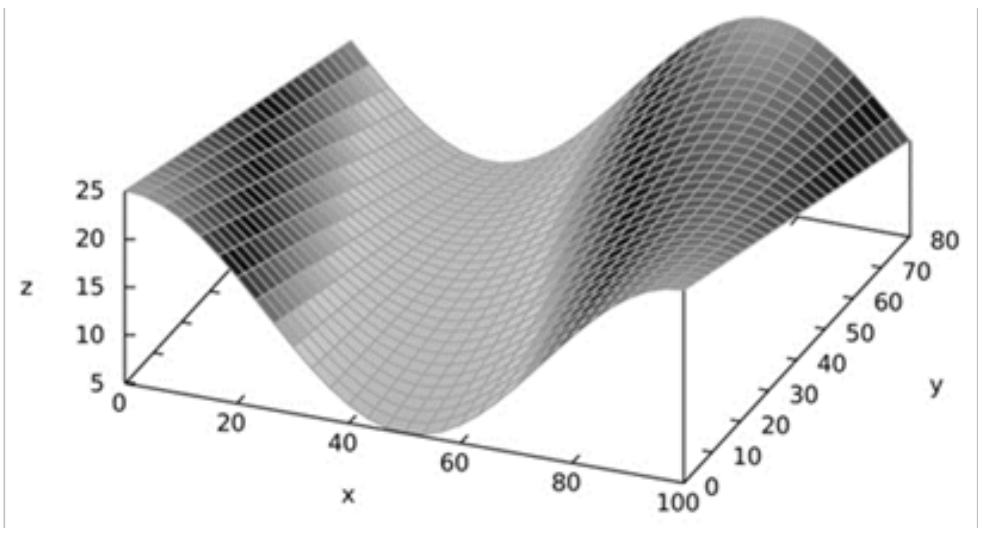

Fig. 9. Free-form surface represented by the function (16) 
Table 1. Adjustment using the Nelder-Mead method

\begin{tabular}{|l|c|c|}
\hline & sc01.dat & sc02.dat \\
\hline$\left(\Delta \mathrm{x}_{\mathrm{w}}, \mathrm{y}_{\mathrm{w}}, \mathrm{a}_{\mathrm{w}}\right)$ & $(0,0,0)$ & $(0,0,0)$ \\
Mean surface distance $[\mathrm{mm}]$ & 0.2786 & 0.30286 \\
Max. positive offset $[\mathrm{mm}]$ & 0.48074 & 0.51429 \\
Max. negative offset $[\mathrm{mm}]$ & -0.44981 & -0.51977 \\
\hline$\left(\Delta \mathrm{x}_{\mathrm{w}}, \mathrm{y}_{\mathrm{w}}, \mathrm{a}_{\mathrm{w}}\right)$ & $(0.7167,0.4973,0.0804)$ & $(0.7617,0.5299,-0.0314)$ \\
Mean surface distance $[\mathrm{mm}]$ & 0.055142 & 0.024572 \\
Max. positive offset $[\mathrm{mm}]$ & 0.17997 & 0.080997 \\
Max. negative offset $[\mathrm{mm}]$ & -0.15617 & -0.12394 \\
\hline Total computation time $[\mathrm{s}]$ & 149.83 & 157.31 \\
Points number & 3708 & 3775 \\
\hline
\end{tabular}

Table 2. Adjustment using the inexact Newton method

\begin{tabular}{|l|c|c|}
\hline & sc01.dat & sc02.dat \\
\hline$\left(\Delta \mathrm{x}_{\mathrm{w}^{\prime}}, \mathrm{y}_{\mathrm{w}}, \mathrm{a}_{\mathrm{w}}\right)$ & $(0.6630,0.5511,0)$ & $(0,0,0)$ \\
Mean surface distance $[\mathrm{mm}]$ & 0.0565 & 0.30223 \\
Max. positive offset $[\mathrm{mm}]$ & 0.17999 & 0.57223 \\
Max. negative offset $[\mathrm{mm}]$ & -0.15741 & -0.62206 \\
\hline Computation time $[\mathrm{s}]$ & 1433.76 & 1438.02 \\
\hline$\left(\Delta \mathrm{x}_{\mathrm{w}}, \mathrm{y}_{\mathrm{w}}, \mathrm{a}_{\mathrm{w}}\right)$ & $(0.7169,0.4973,0.0803)$ & $(0.7166,0.5300,0.0314)$ \\
Mean surface distance $[\mathrm{mm}]$ & 0.055142 & 0.024572 \\
Max. positive ofset $[\mathrm{mm}]$ & 0.17997 & 0.080928 \\
Max. negative offset $[\mathrm{mm}]$ & -0.15617 & -0.12384 \\
\hline Total computation time $[\mathrm{s}]$ & $14.595+27.151=41.746$ & $14.867+27.434=42.301$ \\
C++ computation time $[\mathrm{s}]$ & $0.0208+0.0331=0.0539$ & $0.0194+0.0313=0.0507$ \\
Points number & 3708 & 3775 \\
\hline
\end{tabular}

Table 3. Measurement results interpretation for the whole cloud with and without the workpiece coordinate system adjustment

\begin{tabular}{|l|c|c|}
\hline & sc01.dat & sc02.dat \\
\hline$\left(\Delta \mathrm{x}_{\mathrm{w}}, \mathrm{y}_{\mathrm{w}}, \mathrm{a}_{\mathrm{w}}\right)$ & $(0,0,0)$ & $(0,0,0)$ \\
Mean surface distance $[\mathrm{mm}]$ & 0.27896 & 0.30223 \\
Max. positive offset $[\mathrm{mm}]$ & 0.93423 & 0.57223 \\
Max. negative offset $[\mathrm{mm}]$ & -0.57223 & -0.62206 \\
\hline Computation time $[\mathrm{s}]$ & 1433.76 & 1438.02 \\
\hline$\left(\Delta \mathrm{x}_{\mathrm{w}}, \mathrm{y}_{\mathrm{w}}, \mathrm{a}_{\mathrm{w}}\right)$ & $(0.7169,0.4973,0.0803)$ & $(0.7616,0.5300,0.0314)$ \\
Mean surface distance $[\mathrm{mm}]$ & 0.055683 & 0.024977 \\
Max. positive ofset $[\mathrm{mm}]$ & 0.59395 & 0.23678 \\
Max. negative offset $[\mathrm{mm}]$ & -0.19518 & -0.23627 \\
\hline Computation time $[\mathrm{s}]$ & 1421.13 & 1457.85 \\
C++ computation time $[\mathrm{s}]$ & $12.247+22.480=34.727$ & $12.453+22.771=35.524$ \\
Points number & 3707474 & 3774502 \\
\hline
\end{tabular}




\section{CONCLUSION}

Methods that are used for the evaluation of the form of the workpiece apply a best-fit criterion. Its biggest disadvantage is its use in cases of more significant form deviations. The proposed algorithm deals with this disadvantage and offers a way to solve this problem.

In Table 3 the results for all cloud points with the workpiece coordinate system origin placed at the point $\mathrm{O}_{\mathrm{w}}^{\prime}$ are compared with the results with an adjusted workpiece coordinate system.

One can see that the mean surface distance after the optimal adjustment for the whole cloud is just the same as the value for only thousandth of all points. The maximal positive and negative displacements for all cloud points are, of course, worse than the displacements for only part of the points. However, it is evident that the results both the mean and maximal offsets - without the coordinate system adjustment are much more pessimistic.

\section{Acknowledgements}

This work is a part of projects VEGA 1/0182/15 "Research of strategies: coordinate measurement of free-form surfaces using contact and non-contact measurement system", APVV15-0149 "Research of new measuring methods of machine condition", VEGA 1/0198/15 "Research of innovative methods for emission reduction of driving units used in transport vehicles and optimisation of active logistic elements in material flows in order to increase their technical level and reliability" and VEGA 1/0360/15 "Research of active surfaces preparation for advanced tools manufactured by CNC contour milling".

We also thank CEIT Engineering Services, Ltd. Žilina for cooperation.

\section{REFERENCES}

1. Ohara M., Higashi M. Integration of CAD/CAM systems in automotive body engineering. Computers \& Graphics, 7 (3-4), 1983, 307-311, 313-314.

2. Mehrad V., Xue D., Gu P., Prediction of surface reconstruction uncertainties for freeform surface inspection. Measurement, 46 (8), 2013, 2682-2694.

3. Sitnik R., Błaszczyk P. M. Segmentation of unsorted cloud of points data from full field optical measurement for metrological validation. Computers in Industry, 63 (1), 2012, 30-44.
4. Oe T., Shizuki B., Tanaka J. Scan modeling: 3D modeling techniques using cross section of a shape. Proc. of 10th Asia Pacific Conference on Computer Human Interaction, New York, USA 2012, 243-250.

5. Kruth J.-P., Kerstens A. Reverse engineering modelling of freeform surfaces from point clouds subject to boundary conditions. Journal of Materials Processing Technology, 76 (1-3), 1998, 120-127.

6. Wu N., Yang C., Guo R., Zhang Z., Zhou C., Chen W., Tao L. Reverse Design and Manufacture of the Car Door Using Reverse Engineering Methods. American Society of Civil Engineers, 2011, ch. 384, 3849-3854.

7. Ochiai Y., Sekiya T. Generation of free-form surface in CAD for dies. Advances in Engineering Software, 22 (2), 1995, 113-118.

8. Lo C.-C. CNC machine tool surface interpolator for ball-end milling of free-form surfaces. International Journal of Machine Tools and Manufacture, 40 (3), 2000, 307-326.

9. Wei E.-J., Lin M.-C. Study on general analytical method for $\mathrm{CNC}$ machining the free-form surfaces. Journal of Materials Processing Technology, 168 (3), 2005, 408-413.

10. Sacharow A., Odendahl S., Peuker A., Biermann D., Surmann T., Zabel A. Iterative, simulationbased shape modification by free-form deformation of the NC programs. Advances in Engineering Software, 56 (2013), 63-71.

11. Zhang A. M., Fang D. Y., Qiu Y. Research and practice on new measuring and drafting mode of mechanical drawing based on reverse engineering. Measurement Technology and its Application: Applied Mechanics and Materials, 239, 2013, 645-648.

12. Lee R.-T., Shiou F.-J. Multi-beam laser probe for measuring position and orientation of freeform surface. Measurement, 44 (1), 2011, 1-10.

13. Kale K. B., Gurumoorthy B. Profile tolerance verification for free-form surfaces using medial axis transform. Proc. of 12th CIRP Conference on Computer Aided Tolerancing, 2013, 133-141.

14. Wait R. The Numerical Solution of Algebraic Equations. John Wiley \& Sons, 1979.

15. Nocedal J., Wright S. Numerical optimization. Springer-Verlag, 1999.

16. Bunday B. D. Basic Optimisation Methods. Edward Arnold, 1984.

17. Higham N. J. Optimization by direct search in matrix computations. SIAM Journal on Matrix Analysis and Applications, 14 (2), 1993, 317-333.

18. Kelley C. T. Iterative Methods for Optimization. Frontiers in Applied Mathematics, Society for Industrial and Applied Mathematics, 1999.

19. Molnár V., Fedorko G., Stehlíková B., Michalik P., 
Kopas M. Mathematical models for indirect measurement of contact forces in hexagonal idler housing of pipe conveyor. Meas. J. Int. Meas. Confed., 47, 2014, 794-803.

20. Debski H., Teter A., Kubiak T., Samborski S. Local buckling, post-buckling and collapse of thin-walled channel section composite columns subjected to quasi-static compression. Compos. Struct., 136, 2016.

21. Garbacz T., Jachowicz T., Gajdoš I., Kijewski G. Research on the influence of blowing agent on selected properties of extruded cellular products. Adv. Sci. Technol. Res. J. 28 (9), 2015, 81-88.
22. Král' J.jr, Král' J. Verification of a three axis milling machine accuracy in the process of complex shaped part production. Applied Mechanics and Materials: Novel Trends in Production Devices and Systems. 474, 2014, 261-266.

23. Fedorko G., Král' J.jr, Král’ J., Ristovic I., Molnár V. Determination of calculation for the shape of blades trace in the concrete mixer truck. Procedia Technology, 19, 2015, 395-401.

24. Kulka J., Mantic M., Fedorko G., Molnár V. Analysis of crane track degradation due to operation. Engineering Failure Analysis, 59, 2016, 384-395. 